\title{
TGF $\beta$ signalling plays an important role in IL4-induced alternative activation of microglia
}

\author{
Xiaolai Zhou ${ }^{1,2}$, Björn Spittau ${ }^{1 *}$ and Kerstin Krieglstein ${ }^{1,3^{*}}$
}

\begin{abstract}
Background: Microglia are the resident immune cells of the central nervous system and are accepted to be involved in a variety of neurodegenerative diseases. Several studies have demonstrated that microglia, like peripheral macrophages, exhibit two entirely different functional activation states, referred to as classical (M1) and alternative (M2) activation. TGF $\beta$ is one of the most important anti-inflammatory cytokines and its effect on inhibiting microglia or macrophage classical activation has been extensively studied. However, the role of TGF $\beta$ during alternative activation of microglia has not been described yet.

Methods: To investigate the role of TGF $\beta$ in IL4-induced microglia alternative activation, both, BV2 as well as primary microglia from new born C57BL/6 mice were used. Quantitative RT-PCR and western blots were performed to detect mRNA and protein levels of the alternative activation markers Arginase1 (Arg1) and Chitinase 3-like 3 (Ym1) after treatment with IL4, TGF $\beta$ or both. Endogenous TGF $\beta$ release after IL4 treatment was evaluated using the mink lung epithelial cell (MLEC) assay and a direct TGF $\beta 2$ ELISA. TGF $\beta$ receptor type I inhibitor and MAPK inhibitor were applied to address the involvement of TGF $\beta$ signalling and MAPK signalling in IL4-induced alternative activation of microglia.

Results: TGF $\beta$ enhances IL4-induced microglia alternative activation by strongly increasing the expression of Arg1 and Ym1. This synergistic effect on Arg1 induction is almost completely blocked by the application of the MAPK inhibitor, PD98059. Further, treatment of primary microglia with IL4 increased the expression and secretion of TGF $\beta 2$, suggesting an involvement of endogenous TGF $\beta$ in IL4-mediated microglia activation process. Moreover, IL4-mediated induction of Arg1 and Ym1 is impaired after blocking the TGF $\beta$ receptor I indicating that IL4-induced microglia alternative activation is dependent on active TGF $\beta$ signalling. Interestingly, treatment of primary microglia with TGF $\beta$ alone results in up regulation of the IL4 receptor alpha, indicating that TGF $\beta$ increases the sensitivity of microglia for IL4 signals.

Conclusions: Taken together, our data reveal a new role for TGF $\beta$ during IL4-induced alternative activation of microglia and consolidate the essential functions of TGF $\beta$ as an anti-inflammatory molecule and immunoregulatory factor for microglia.
\end{abstract}

Keywords: Microglia, TGFß, IL4, Alternative activation, Arg1, Ym1

\footnotetext{
* Correspondence: bjoern.spittau@anat.uni-freiburg.de; kerstin.krieglstein@ anat.uni-freiburg.de

${ }^{1}$ Institute for Anatomy and Cell Biology, Department of Molecular Embryology, Albert-Ludwigs-University Freiburg, Albertstraße 17, Freiburg 79104, Germany

${ }^{3}$ Freiburg Institute for Advanced Studies (FRIAS), Albert-Ludwigs-University

Freiburg, Albertstraße 19, Freiburg 79104, Germany

Full list of author information is available at the end of the article
} 


\section{Background}

Microglia represent the resident immune cells of the central nervous system (CNS) and account for approximately $12 \%$ of all cells in the brain [1]. As counterparts of peripheral macrophages, microglia sense the brain parenchyma for perturbations resulting from injury or pathological conditions. Several CNS neurodegenerative pathologies including Alzheimer's disease (AD) [2-4], multiple sclerosis (MS) [5,6] and Parkinson's disease (PD) $[7,8]$ are characterised by a strong microglia reaction that is, at least partially, responsible for the progressive nature of these diseases.

Increasingly, studies have demonstrated that microglia, like peripheral macrophages, exhibit two entirely functional different activation states that are referred to as classical and alternative activation. The classical activation of microglia (M1) is induced by Th1 cytokines, such as IFN $\gamma$, IL1 $\beta$, IL12, and IL6 as well as lipopolysaccharide (LPS) and results in production and release of pro-inflammatory cytokines such as tumour necrosis factor-alpha (TNF $\alpha)$, IL6, matrix metalloproteinase (MMP)-9, nitric oxide (NO) and reactive oxygen/nitrogen species (ROS) [9-11] which are involved in inflammation-mediated neurotoxicity [12-14]. Whereas alternative activation of microglia (M2) initiated by Th2 cytokines, such as IL4 and IL13, as well as IL10 and TGF $\beta$, results in up regulation of arginase-1 (Arg1), Chitinase 3 like 3 (Ym1) and found in inflammatory zone-1 (Fizz1), which are primarily associated with tissue repair and extracellular matrix composition [3,11]. As hypothesised by Town et al. these differently activated microglia likely exist as a dynamic continuum in vivo, with functions ranging from deleterious to beneficial $[15,16]$. All these notions suggest that modulating microglia activation states might be a potential therapeutic approach to different types of neurodegenerative diseases including $\mathrm{AD}, \mathrm{MS}$, and $\mathrm{PD}$.

Based on the M1 and M2 activation states, a more detailed categorization of macrophage activation states has recently been discussed. As suggested by Gordon and colleagues $[11,17,18]$, alternative activation is only limited to macrophages treated with IL4 or IL13 and is primarily associated with injury resolution including tissue repair and extracellular matrix reconstruction. While IL10 and TGF $\beta$ promote a macrophage phenotype characterised by inflammation resolution including inhibition of pro-inflammatory cytokine production, modification of inflammatory signalling pathways and increased expression of scavenger receptors, thereby, promoting debris clearance. This type of activated macrophage has been termed acquired deactivation [19-23]. Whereas IL10 and TGF $\beta$ induce acquired deactivation, the acquired deactivation macrophages can further produce IL10 and TGF $\beta$ in an autocrine manner $[3,24,25]$. Regarding the immunoregulatory function of
IL10 and TGF $\beta$ produced by the acquired deactivation macrophages, this phenotype of macrophages has been also named as a regulatory macrophage by Mosser and Edwards [24]. Although these studies promoted the knowledge of microglia/macrophage activation phenotypes and their distinct functions, there is still no general agreement in the field on the nomenclature and, more importantly, the interaction between different activation states of microglia/ macrophages is still poorly understood.

TGF $\beta$ is a multifunctional cytokine involved in a variety of physiological and pathological conditions [26]. TGF $\beta$ s bind to the TGF $\beta$ receptor type II, which recruits and phosphorylates a type I receptor. The type I receptor then phosphorylates $\operatorname{Smad} 2 / 3$, which further bind to Smad4 to form a heteromeric complex that translocates into the nucleus to regulate the expression of target genes $[27,28]$. Next to the canonical Smad-dependent pathway, TGF $\beta$ s also signal via Smad-independent signalling cascades, including mitogen-activated protein kinase signalling (MAPK) pathways [29].

In this study we used the microglial cell line BV2 and primary microglia to investigate the role of TGF $\beta$ in IL4-induced alternative activation, thereby illustrating the interaction between different microglia/macrophage activation states. For the first time, we provide evidence that although TGF $\beta 1$ treatment alone is not able to induce microglia, alternative activation, treated together with IL-4, strongly enhances IL4-induced alternative microglia activation. Arg1 and Ym1 expression was significantly increased after co-treatment with IL4 and TGF $\beta 1$. To our surprise, Arg1 and Ym1 expression induced by IL4 treatment alone was significantly impaired in the presence of the TGF $\beta$ receptor type I inhibitor. Further investigation revealed that IL4 treatment alone increased microglial TGF 32 expression and secretion, which in turn might promote IL4-induced Arg1 and Ym1 expression. Moreover, we found TGF $\beta 1$ treatment resulted in up regulation of the IL4 receptor alpha (IL4R $\alpha$ ). Finally, we provide evidence that the Mitogenactivated protein kinase (MAPK) pathway is essential for TGF $\beta$-mediated enhancement of Arg1 expression after IL4 treatment in microglia.

\section{Methods}

\section{Cytokines and reagents}

All reagents for cell culture, namely Trypsin-EDTA $1 \times$, Hank's balanced salt solution (BSS), Dubecco's modified Eagle medium (DMEM)-Ham's F12, penicillin/streptomycin (P/S) 100×, and fetal calf serum (FCS) were purchased from PAA Laboratories (Cölbe, Germany). MAPK/ERK (MEK) inhibitor PD98059 and poly-D-lysine were purchased from Sigma-Aldrich (Deisenhofen, Germany). Recombinant murine IL4 and recombinant human TGF $\beta 1$ were purchased from PeproTech (Hamburg, Germany). 
TGF $\beta$ receptor type I kinase inhibitor (T $\beta \mathrm{KI}$ ) was obtained from Merck Chemicals (Darmstadt, Germany). Primary antibodies: anti-Arginase1, anti-IL4R $\alpha$, antiTGFB2 and anti-Smad1/2/3 were purchased from SantaCruz (Heidelberg, Germany). Phospho-Smad2Ser465/467 and phospho-Stat6-Tyr641 were obtained from New England Biolabs (Frankfurt, Germany), Ym1 antibody was from StemCell Technologies (Grenoble, France). GAPDH was purchased from Abcam (Cambridge, UK). Goat anti-mouse $\mathrm{Cy} 3$, goat anti-rabbit $\mathrm{Cy} 3$ were from Dianova (Hamburg, Germany).

\section{BV2 cell culture}

The murine microglia cell line BV2 was maintained in DMEM/F12 (PAA) supplemented with $10 \%$ heatinactivated FCS and $1 \% \mathrm{P} / \mathrm{S}$. Cultures were kept at $37^{\circ} \mathrm{C}$ in $5 \% \mathrm{CO}_{2} / 95 \%$ humidified air atmosphere. Prior to treatment cells were washed with PBS and serum-free medium was added.

\section{Primary microglia cultures}

Whole brains obtained from P0/1 C57BL/6 mice were washed twice with Hank's BSS solution and vessels and meninges were removed from brain surfaces under the microscope. Cleaned brains were collected and enzymatically dissociated with Trypsin-EDTA $(1 \times)$ for 15 minutes at $37^{\circ} \mathrm{C}$. An equal amount of ice-cold FCS, together with DNase I (Roche Diagnostics, Mannheim, Germany) at a final concentration of $0.5 \mathrm{mg} / \mathrm{ml}$ was added prior to dissociation with wide- and narrow-bored polished Pasteur pipettes. Cells were then washed and single cells were centrifuged, collected and suspended with (DMEM)-Ham's F12 medium containing 10\% fetal bovine serum (FBS) and 1\% Penicillin/Streptomycin. Cell suspensions were transferred to poly-D-lysine-coated tissue culture flasks with a density of 2 brains $/ 75 \mathrm{~cm}^{2}$ flask. Cultures were maintained in a humidified $5 \% \mathrm{CO}_{2} / 95 \%$ air atmosphere at $37^{\circ} \mathrm{C}$. At day in vitro (DIV) 2 and 3, cultures were washed twice with pre-warmed phosphatebuffered saline (PBS) and fresh culture medium was added. After 10 to 14 days in culture, microglia were shaken off from adhesive grown astroglia by shaking at approximately 250 to $300 \mathrm{rpm}$ for 1 hour. Isolated microglia were plated into various dishes or plates and treated with proper factors, according to different experimental purposes.

\section{Immunocytochemistry}

Microglia were plated on glass coverslips and were fixed after treatment with $4 \%$ paraformaldehyde (PFA) for 15 minutes at room temperature. After blocking with PBS containing $10 \%$ normal goat serum and $0.1 \%$ TritonX-100 (Roche, Mannheim, Germany) for 1 hour at room temperature, cells were incubated with primary antibodies at $4^{\circ} \mathrm{C}$ overnight, followed by an incubation with corresponding Cy3-conjugated secondary antibodies (goat anti-mouse Cy3 1:100, goat anti-rabbit Cy3 1:100). Nuclei were counterstained using 4/,6-diamidino2-phenylindole (DAPI, Roche). Phase contrast and fluorescence images were captured using the Leica AF6000 imaging system (LEICA, Wetzlar, Germany).

\section{Protein isolation and western blotting}

Total proteins were isolated from primary microglia and BV2 cells after washing with PBS and incubation with ice-cold mammalian protein extraction reagent (M-PER, Thermo Scientific, Bonn, Germany) plus Complete Protease Inhibitor (Roche) with gentle up and down shaking for 5 minutes. The supernatant as well as debris were collected, and centrifuged at 14,000 rpm for 8 minutes to obtain the supernatant, which contains proteins. After determination of protein concentrations, 10-15 $\mu \mathrm{g}$ total proteins were loaded onto 10 to $12 \%$ SDS gels. After electrophoresis, proteins were transferred to polyvinylidene difluoride (PVDF) membranes (Immobilon, Milipore, Schwalbach, Germany). Blots were blocked with $5 \%$ non-fat dry milk in Tris-buffered saline containing 0.05\% Tween-20 (TBST) for $1 \mathrm{~h}$ and incubated with primary antibodies overnight at $4^{\circ} \mathrm{C}$. Primary antibodies against Arginase-1 (rabbit polyclonal, 1:1000, SantaCruz), phospho-Smad2 (Ser465/467) (rabbit, 1:1000, Cell Signaling), phospho-Stat6 (Tyr641) (rabbit, 1:1000, Cell Signaling), IL4R $\alpha$ (mouse, 1:1000, SantaCruz), TGF 32 (rabbit polyclonal, 1:1000, SantaCruz), Ym1 (rabbit polyclonal, 1:1000, StemCell Technologies) and glyceraldehyde-3-phosphate dehydrogenase (GAPDH) (mouse monoclonal, 1:10,000, Abcam, Cambridge, UK) were used. After incubation with goat anti-rabbit or goat anti-mouse IgG horseradish peroxidase (HRP)-linked antibodies (1:10,000, Cell Signaling), blots were developed using Western Lightning ${ }^{\circledR}$ Plus-ECL, Enhanced Chemiluminescence Substrate (Perkin-Elmer, Rodgau, Germany). Signals were captured on Amersham Hyperfilm ${ }^{\mathrm{TM}}$ ECL (GE Healthcare, München, Germany). Band intensities were evaluated using the software FlourChem 8800 (Alpha Innotech, Biozym, Olendorf, Germany).

\section{RNA isolation and quantitative RT-PCR}

RNA was isolated from BV2 and primary microglial cells with the RNeasy kit (Qiagen, Hilden, Germany), according to the manufacturer's instructions. RNA was reverse transcribed to cDNA with the GeneAmp RNA PCR Core Kit (Applied Biosystems, Darmstadt, Germany). Quantitative RT-PCR (qRT-PCR) analysis was performed with the $\mathrm{MyiQ}^{\mathrm{sm}}$ (BIO-RAD, München, Germany) and the Quantitect SYBR Green PCR Kit (Applied Biosystems) with $1 \mu \mathrm{l}$ of cDNA template in a $25 \mu$ l reaction mixture. Results were analysed with the Bio-Rad iQ5 
Opitcal System Software and the comparative CT method. Data are expressed as $2^{-\Delta \Delta C T}$ for the experimental gene of interest normalized to the housekeeping gene (GAPDH) and presented as fold change relative to control. The following primers were used: TGF $\beta 1$ for: $5^{\prime}$ TAATGGTGGACCGCAACAACG-3; TGF 31 rev: 5'-TC CCGAATGTCTGACGTATTGAAG-3 [NM_011577.1, NCBI]; TGF $\beta 2$ for: 5 -AGAATCGTCCGCTTTGATG TCTC-3', TGF 32 rev: $5^{\prime}$-ATACAGTTCAATCCGCTGCT CG-3' [NM_009367.3, NCBI]; TGF $\beta 3$ for: 5'-GCCCTGG ACACCAATTACTGC-3; TGFß3rev: 5'-CCTTAGGTT CGTGGACCCATTTC-3' [NM_009368.3, NCBI]; Arg1for: 5'-TCATGGAAGTGAACCCAACTCTTG-3', Arg1rev: 5'-TCAGTCCCTGGCTTATGGTTACC-3' [NM_007482.3, NCBI]; Ym1for: 5'-AGACTTGCGTGACTATGAAGCA TTG-3'; Ym1rev: 5'-GCAGGTCCAAACTTCCATCCTC$3^{\prime}$ [NM_009892.2, NCBI]; IL4for: 5'-ATTTTGAACGAGG TCACAGGAGAAG-3'; IL4rev: 5'-ACCTTGGAAGCCC TACAGACGAG-3' [NM_021283.2, NCBI]; IL4Rofor: 5'GAACTCAGACCCACCCAAAAGC-3'; IL4Rorev: 5'-A AGTGGCAAGTGAGGGACGAG-3' [NM_001008700.3, NCBI]; Gapdhfor: 5'-ATGACTCTACCCACGGCAAG-3'; Gapdhrev: 5'-GATCTCGCTCCTGGAAGATG-3' [NM 008084.2, NCBI].

\section{Characterisation of TGF $\beta$ secretion}

Primary microglia were treated with or without IL4 $(10 \mathrm{ng} / \mathrm{ml})$ in serum-free DMEM-Ham's F12 medium for 24 hours. Conditioned medium was collected for the mink lung epithelial cell (MLEC) assay and ELISA. The MLEC assay is widely used to measure the amount of TGF $\beta$ s in conditioned medium. The principal is that the MLECs containing a luciferase reporter under the control of a TGF $\beta$-responsive truncated plasminogen activator inhibitor (PAI)-promoter are able to generate luciferase with a TGF $\beta$ s dose-dependent manner. Since the MLECs only response to the activated TGF $\beta \mathrm{s}$, in order to detect the latent part of TGF $\beta$ s, the conditioned medium has to be acidification first to convert latent TGF $\beta$ s into activated ones. To evaluate the levels of released TGF $\beta$ s after IL4 treatment, the MLEC assay was performed as described by Abe et al. [30]. Briefly, MLECs were placed into 96-well plates at the density of $1.5 \times 10^{4}$ cells per well and treated with collected conditioned medium either with or without acidification with $1 \mathrm{M} \mathrm{HCL}$ and $\mathrm{pH}$ adjustment with $\mathrm{NaOH}$ (to activate latent $\mathrm{TGF} \beta \mathrm{s}$ ) as well as the standard mediums containing different contractions of recombinant TGF $\beta$ for 16 hours. Cells were washed with PBS and total proteins were extracted using lysis buffer (Tropix, Applied Biosystems). The luciferase activity was analysed in duplicates using a luminometer (LumatB5076, Berthold, Bad Wildbad, Germany).

\section{Direct enzyme-linked immunosorbent assay for TGF $\beta 2$ detection}

Conditioned media collected from primary microglia after treatment with and without IL4 $(10 \mathrm{ng} / \mathrm{ml})$, as well as diluted recombinant human TGF $\beta 2$ (2000, 1000, 500, 250, 125, 62.5 and 31.25 pg, R\&D Systems, WiesbadenNordenstedt, Germany) standard solutions, were added into ELISA plates (NUNC, Wiesbaden, Germany) and incubated overnight at $4^{\circ} \mathrm{C}$. After washing with washing buffer $(0.05 \%$ Tween-20 in PBS) and blocking with $1 \%$ $\mathrm{BSA}$ in PBS for 2 hours at $37^{\circ} \mathrm{C}$, the plates were incubated with anti-TGF $\beta 2$ (Santa Cruz) primary antibodies overnight at $4^{\circ} \mathrm{C}$. Followed by washing and incubation with Biotin-linked anti-rabbit secondary antibodies for 2 hours at $37^{\circ} \mathrm{C}$, plates were incubated with $\mathrm{ABC}$ solution (Vectashield, BIOZOL, Eching, Germany). Colour reaction was performed using 2, 2'-azino-bis (3ethylbenzothiazoline-6-sulphonic acid) substrate (ABTS, Sigma-Aldrich, Deisenhofen, Germany) for 30 minutes in the dark. Finally, absorbance was detected using an FC Multiskan plate reader (Thermo Fischer, Bonn, Germany) at the absorption of $405 \mathrm{~nm}$.

\section{Cytokine array}

For the analysis of IL4 release, supernatant from untreated and TGF $\beta 1$-treated primary microglia was analysed using the Proteome Profiler ${ }^{\mathrm{mi}}$ Array Mouse Cytokine Array Panel A (R\&D Systems, WiesbadenNordenstedt, Germany) according to the manufacturer's instructions. Briefly, equal amounts of primary miroglia cells were incubated for 24 hours in the presence or absence of TGF $\beta 1$ and media were collected. Cytokine array membranes were incubated with cell culture supernatants at $4^{\circ} \mathrm{C}$ overnight with gentle shaking. Membrane signals were developed using Western Lightning ${ }^{\circledR}$ Plus-ECL, Enhanced Chemiluminescence Substrate (Perkin-Elmer, Germany) and signals were captured on Amersham Hyperfilm $^{\text {sin }}$ ECL (GE Healthcare).

\section{Statistical procedures}

The data were expressed as means \pm standard error (SE). Statistical significance between multiple groups was compared by one-way analysis of variance (ANOVA) followed by an appropriate multiple comparison test. Twogroup analysis was performed using the Student's $t$-test. $P$-Values $<0.05$ were considered statistically significant. All statistical analyses were performed using GraphPad Prism4 software (GraphPad Software Inc.).

\section{Results}

TGF $\beta 1$ enhances IL4-induced alternative microglia activation

To investigate the influence of TGF $\beta 1$ on IL4-induced microglia-alternative activation, primary microglia were 
treated either with IL4 $(10 \mathrm{ng} / \mathrm{ml})$, TGF $\beta 1(1 \mathrm{n} \mathrm{g} / \mathrm{ml})$ or with a combination of both factors for 24 hours. As a crude readout for microglia activation, the morphology change of microglia was analysed after treatment. Treatment with IL4 or TGF $\beta 1$ alone for 24 hours resulted in morphology changes in BV2 cells (data not shown) and primary microglia towards a more ramified phenotype. This extent of morphological change was remarkably increased when the cells were treated with IL4 and TGF $\beta 1$ together (Figure 1A). As the morphological change could not always precisely reflect the activation states, the assessment of the alternative activation still relied on the molecule markers such as Arg1 and Ym1. Therefore, the expression of Arg1 and Ym1 were analysed. Immunofluorescence staining demonstrated increased Arg1 staining intensity after IL4 treatment.
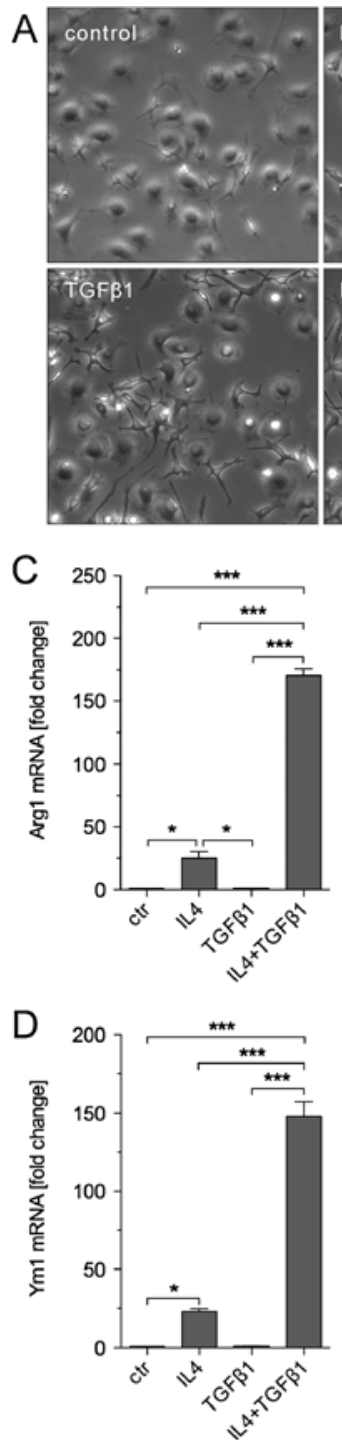
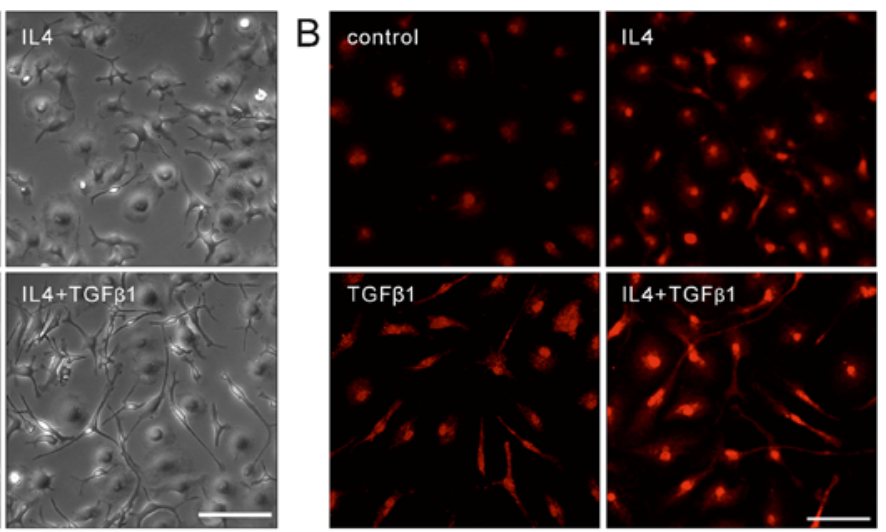

E

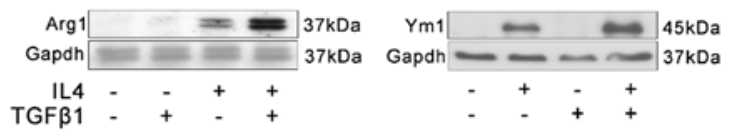

$\mathrm{F}$
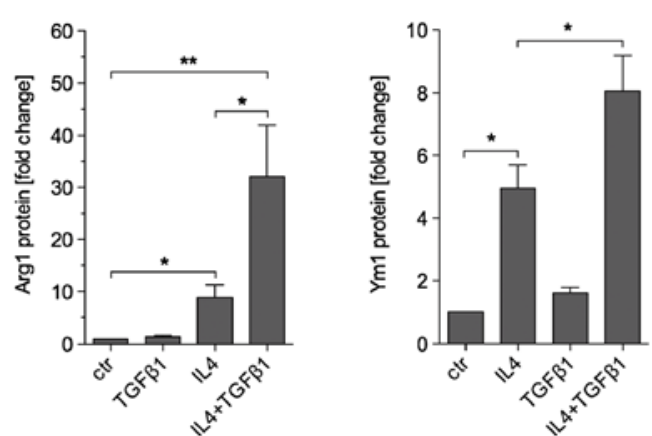

Figure 1 TGF $\beta 1$ enhances IL4-induced alternative activation of microglia. (A) Primary cultured microglial cells changed their morphology from round-shaped into ramified after treated with IL4 $(10 \mathrm{ng} / \mathrm{ml})$ and TGF $\beta 1(1 \mathrm{ng} / \mathrm{ml})$ for 24 hours. This cellular morphological change was enhanced when microglia were co-treated with IL4 and TGF $\beta$ 1. (B) Immunofluorescence staining for Arg 1 demonstrated increased staining intensity for Arg1 after treatment with IL4 or TGF $\beta$ alone. Combined treatment with IL4 and TGF $\beta 1$ strongly enhanced Arg1 immunoreactivity. Scale bars indicate $100 \mu \mathrm{m}$. Quantitative RT-PCR showed increased Arg1 (C) and Ym1 (D) mRNA levels in primary microglia after IL4 treatment. Co-treatment with IL4 and TGFB1 for 24 hours significantly increased Arg1 and Ym1 mRNA levels in primary microglia. (E) Western blotting revealed increased Arg1 and Ym1 protein levels in primary microglia after treatment with IL4. Again, co-treatment with IL4 and TGF $\beta 1$ increased the protein levels of Arg1 and Ym1. Representative western blot results from at least three independent experiments are shown. GAPDH was used as control for equal protein loading. (F) Densitometric evaluation of Arg1 and Ym1 band intensities and statistical analysis. Data are given as means \pm standard error from three independent experiments: ${ }^{*} P<0.05,{ }^{* *} P<0.01,{ }^{* * *} P<0.001$ (one-way analysis of variance). 
Combination of IL4 and TGF $\beta 1$ further increased the staining intensity (Figure 1B). Using quantitative RTPCR the up regulation of Arg1 and Ym1 was determined. A significant increase in Arg1 and Ym1 RNA levels was observed after treatment with IL4 alone. TGF $\beta 1$ treatment alone did not result in increased Arg1 and Ym1 mRNA levels $(P>0.05)$. However, treatment with IL4 and TGF $\beta 1$ resulted in significant increase of Arg1 and Ym1 RNA levels $(P<0.001)$ compared to IL4 treatment alone (Figure 1C, D). As shown in Figure 1E and F, IL4 treatment significantly increased Arg1 and Ym1 protein levels in primary microglia $(P<0.05)$. TGF $\beta 1$ slightly increased Arg1 and Ym1 protein levels in primary microglia, without reaching significant differences compared to control $(P>0.05)$. Combination of
IL4 and TGF $\beta 1$ significantly increased IL4-induced Arg1 and $\mathrm{Ym} 1$ protein levels in primary microglia $(P<0.05)$.

\section{IL4-induced Arg1 and Ym1 upregulation is dependent on TGF $\beta$ signalling}

In order to address whether endogenous TGF $\beta$ signalling is involved in IL4-induced alternative microglia activation, primary microglia were treated with the combination of IL 4 and TGF $\beta$ type I receptor kinase inhibitor IV (T $\beta K \mathrm{~K})$. We found expression of Arg1 and Ym1 induced by IL4 were partially impaired by T $\beta K \mathrm{KI}$. As is shown in Figure 2, primary microglia were treated either with IL4 $(10 \mathrm{ng} / \mathrm{ml})$ or IL4 $(10 \mathrm{ng} / \mathrm{ml})$ together with $\mathrm{T} \beta \mathrm{KI}(2 \mu \mathrm{M} / \mathrm{ml})$ for 24 hours, there the mRNA and pro-
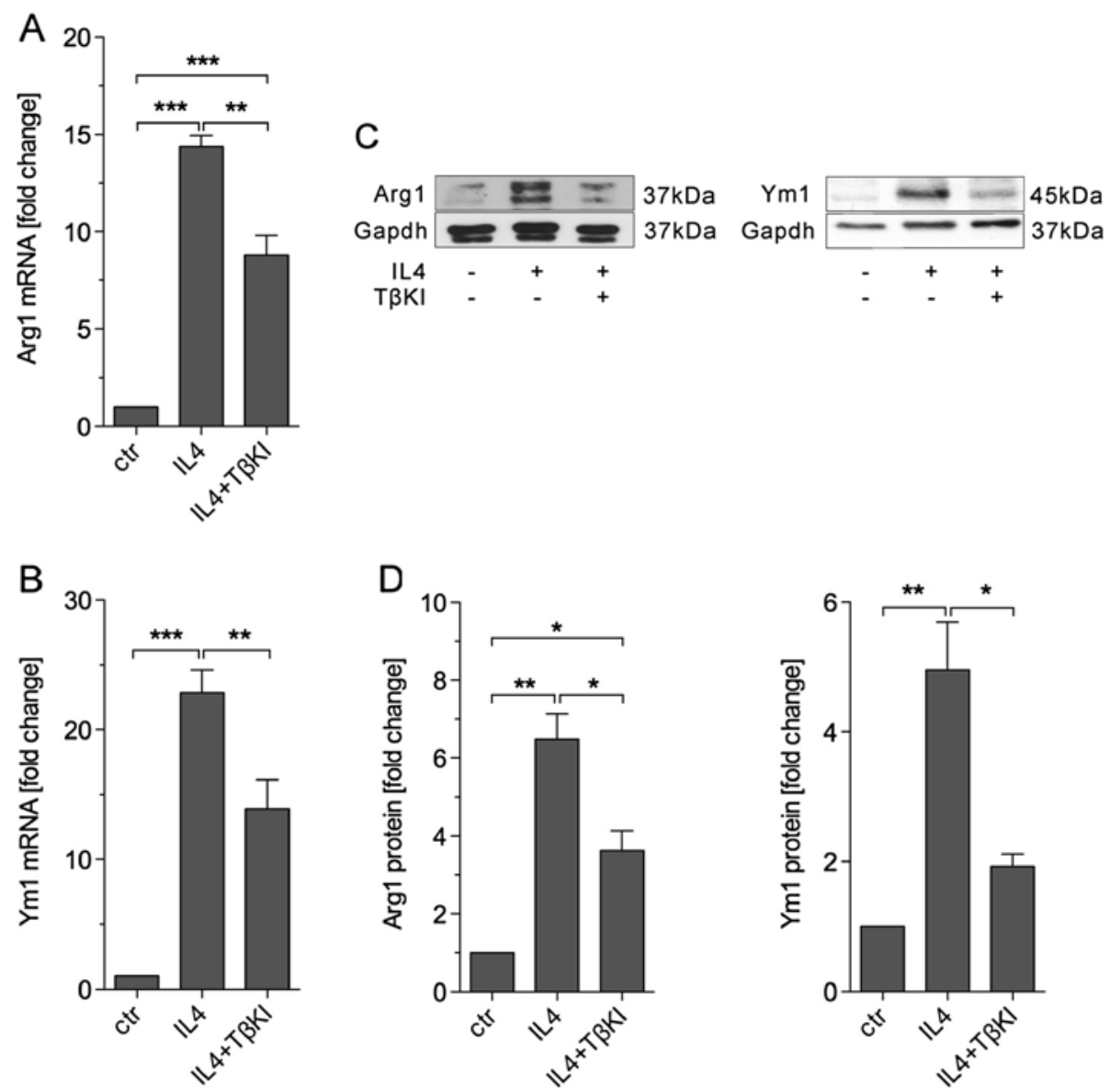

Figure 2 Arg1 and Ym1 expression induced by IL4 was blocked in the presence of a TGF $\beta$ receptor type I inhibitor. Primary microglia were treated with IL4 $(10 \mathrm{ng} / \mathrm{ml})$ combined either with or without TGF $\beta$ receptor type I kinase inhibitor IV (TRKI, $2 \mu M)$ for 24 hours. RNA and proteins were isolated for quantitative RT-PCR and western blotting, respectively. Quantitative RT-PCR shows that IL4 treatment significantly increased $\operatorname{Arg} 1(\mathbf{A})$ and $Y m 1(\mathbf{B})$ mRNA levels $(P<0.001)$ which was partially blocked by co-treatment with TRKI $(P<0.01)$. Western blotting $(\mathbf{C})$ shows Arg1 and Ym1 protein levels in primary microglia after different treatments, which were quantified by densitometric analysis, and normalized to Gapdh (D). IL4 treatment significantly increased Arg1 and Ym1 protein levels in primary microglia $(P<0.01)$, which was significantly blocked by T $\beta K \mathrm{~K}$ in microglia $(P<0.05)$. Data are presented as mean \pm standard error from three independent experiments: ${ }^{*} P<0.05$, ${ }^{* *} P<0.01$, ${ }^{* * *} P<0.001$ (one-way analysis of variance). 
qRT-PCR revealed that Arg1 and Ym1 mRNA up regulation after IL4 treatment was significantly reduced by cotreatment with T $\beta K I$ (Figure 2A, B). Western blotting results demonstrate that Arg1 and $\mathrm{Ym} 1$ protein levels in primary microglia were increased after IL4 treatment and significantly decreased in the presence of T $\beta K \mathrm{I}$ (Figure 2C, D). Similar results have been achieved from BV2 cells (data not shown). All these data indicate that IL4-induced Arg1 and Ym1 expression is at least partially dependent on endogenous TGF $\beta$ signalling in microglia after IL4 treatment.

\section{IL4-treated microglia increase TGF $\beta 2$ expression and secretion}

To investigate the endogenous TGF $\beta$ s expression and secretion form microglia after IL4 treatment, primary microglia were treated with or without IL4 $(10 \mathrm{ng} / \mathrm{ml})$ for 24 hours. The cells were harvested for mRNA extraction and qRT-PCRs for different isoforms of TGF $\beta$ were performed. Quantitative RT-PCR demonstrates that among all TGF $\beta$ isoforms, only TGF $\beta 2$ mRNA was significantly up regulated after IL4 treatment (Figure 3A,B, C). Since the TGF $\beta$ receptor inhibitor used above is not specific for TGF $\beta 1,2$ or 3 , in addition to the blockage of TGF $\beta 1,2,3$, it also inhibits Activin and Nodal signalling. Therefore, the mRNA levels of the Activin A, Activin B, and Nodal were also analysed using qRT-PCR but were not changed after IL4 treatment (data not shown). The protein levels of intracellular TGF $\beta 2$ were significantly increased $(P=0.028)$ after treatment with IL4 (Figure 3D). Since endogenous TGF $\beta 2$ in primary microglial cells is up regulated after IL4 treatment, we further addressed whether TGF $\beta$ secretion from IL4-treated microglia is also increased. Therefore, the conditioned media from IL4-treated (MCM-IL4) as well as nontreated microglial cells (MCM) were harvested after 24 hours and the MLEC assay was performed to monitor TGF $\beta$ secretion. Quantification of TGF $\beta$-induced intensity of luciferase shows that primary microglia secreted TGF $\beta$ under basal conditions and most of this was in a latent and inactive state. IL4 treatment significantly increased latent TGF $\beta$ secretion (Figure 3E). Since the MLEC assay is not specific for different TGF $\beta$ isoforms, based on the qRT-PCR results we used a direct ELISA for TGF $\beta 2$ and demonstrated a significant increase in TGF $\beta 2$ secretion after IL4 treatment (Figure 3F).

\section{TGF $\beta 1$ increases IL4Ra expression in primary microglia}

Based on our observation that TGF $\beta 1$ also enhances the IL13-induced Arg1 up regulation in BV2 cells and primary microglia (data not shown), as well as the knowledge that IL4 and IL13 share the IL4R $\alpha$ as a common receptor, which promotes phosphorylation of the transcription factor Stat6 that finally induces Arg1 expression [11,31], we analysed whether IL4R $\alpha$ is regulated by TGF $\beta 1$. Primary microglia were treated with TGF $\beta 1(1 \mathrm{ng} / \mathrm{ml})$ for different time points and RNA and proteins were isolated. The qRT-PCR results demonstrate that TGF $\beta 1$ treatment significantly increased the mRNA levels of IL4R $\alpha$ after 2 and 4 hours, with the peak at 2 hours. From 6 to 24 hours the levels decreased and finally returned to basal levels at 24 hours after TGF $\beta 1$ treatment (Figure 4A). Western blotting confirmed the TGF $\beta 1$-mediated up regulation of IL4R $\alpha$. IL4R $\alpha$ protein levels increased after treatment with TGF $\beta 1$ reaching the maximum from 6 to 12 hours. After treatment for 24 hours, IL $4 R \alpha$ protein levels returned to basal levels (Figure 4B). Immunostaining for IL4R $\alpha$ after treatment with TGF $\beta 1$ for 6,12 and 24 hours showed a similar pattern. IL4R $\alpha$ staining intensity was increased 6 and 12 hours after treatment with TGF $\beta 1$. After 24 hours, the IL4R $\alpha$ signal was comparable to the control condition (Figure 4C). We further analysed whether TGF $\beta 1$ has an effect on microglial IL4 expression and release. As shown in Figure 4D and E, IL4 mRNA levels were not significantly changed after TGF $\beta 1$ treatment for 24 hours. Using a mouse-specific cytokine array, we revealed that primary microglia release very low levels of IL4 and treatment of primary microglia with TGF $\beta 1$ did not result in any changes in IL4 release after 24 hours. These data suggest that the enhancement of Arg1 and Ym1 expression by TGF $\beta$ in IL4-treated microglia might, at least partially, be mediated by increasing IL4R $\alpha$ expression, thus, enhancing the microglial sensitivity to IL4 signals.

\section{Mitogen-activated protein kinase mediates TGF $\beta 1$-enhanced Arg1 expression in IL4-treated primary microglia}

To investigate the pathways involved in TGF 1 1mediated enhancement of IL4-induced Arg1 expression, the TGF $\beta /$ Smad and the IL4/Stat6 signalling pathways were analysed by monitoring Smad2/3 nuclear accumulation and phosphorylation of Smad2 and Stat6, respectively. Whereas treatment of primary microglia with TGF $\beta 1$ resulted in increased nuclear accumulation of Smad2/3, IL4 treatment failed to induce nuclear accumulation of $\mathrm{Smad} 2 / 3$ (Figure $5 \mathrm{~A}$ ). Immunoblotting against phospho-Smad2 and phospho-Stat6 revealed that TGF $\beta 1$ exclusively increased the levels of phosphorylated Smad2 and failed to increase the levels of phosphorylated Stat6. Vice versa, IL4 treatment resulted in increased levels of phospho-Stat6, whereas phosphorylation of Smad2 was not observed after treatment with IL4 for 1 and 2 hours (Figure 5B).

MAPK has been shown to be activated in microglia after TGF $\beta 1$ treatment [32]. To analyse the role of MAPK signalling on TGF $\beta 1$-mediated enhancement of IL4-induced Arg1 expression, BV2 cells and primary 

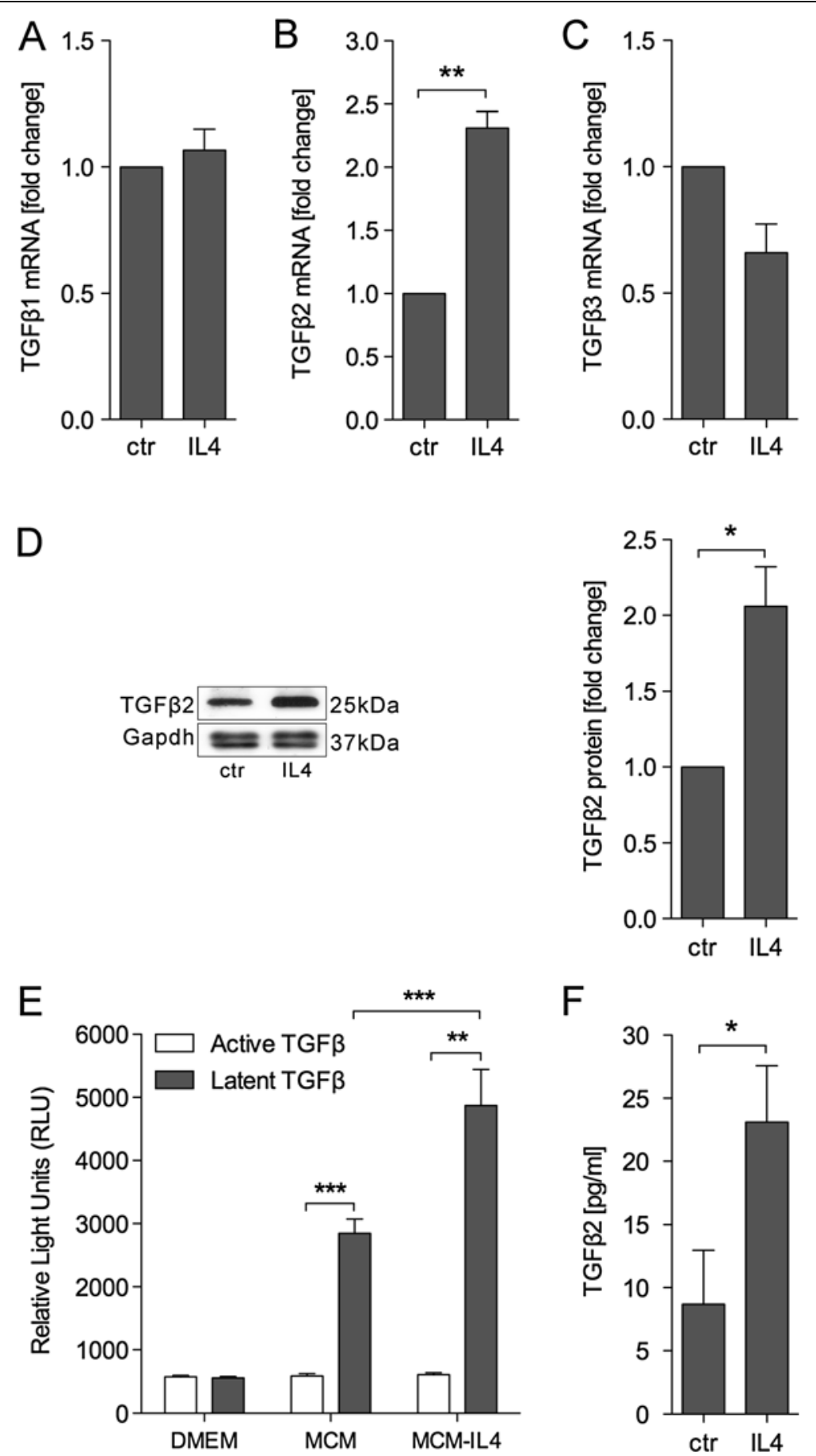

Figure 3 Treatment of microglia with IL4 increased TGF $\beta 2$ expression and secretion. Primary microglia were treated with or without IL4 $(10 \mathrm{ng} / \mathrm{ml})$ for 24 hours. Total mRNA and proteins were isolated from the cells for RT-PCR and western blotting, respectively. Conditioned medium from IL4-treated microglia (MCM-IL4) as well as non-treated microglia (MCM) was collected and the mink lung epithelial cell (MLEC) assay and enzyme-linked immunosorbent assay (ELISA) were performed. Quantitative RT-PCR for TGF $\beta 1$ (A), TGF 32 (B) and TGF $\beta 3$ (C) revealed increased TGF $\beta 2$ expression after IL4 treatment. Intracellular TGF $\beta 2$ protein levels were significantly increased $(P<0.05)$ in primary microglia after treatment with IL4 (D). MLEC assay (E) shows that primary microglia secreted a certain amount of inactive TGF $\beta$, which was significantly increased by IL4 treatment $(P<0.01)$. Direct TGF $\beta 2$ ELISA $(\mathbf{F})$ showed that TGF $\beta 2$ secretion was significantly increased after IL4 treatment $(P<0.05)$. All experiments were repeated at least three times. Data are presented as mean \pm standard error: ${ }^{*} P<0.05,{ }^{* *} P<0.01,{ }^{* * *} P<0.001$ (Student's $t$-test). 

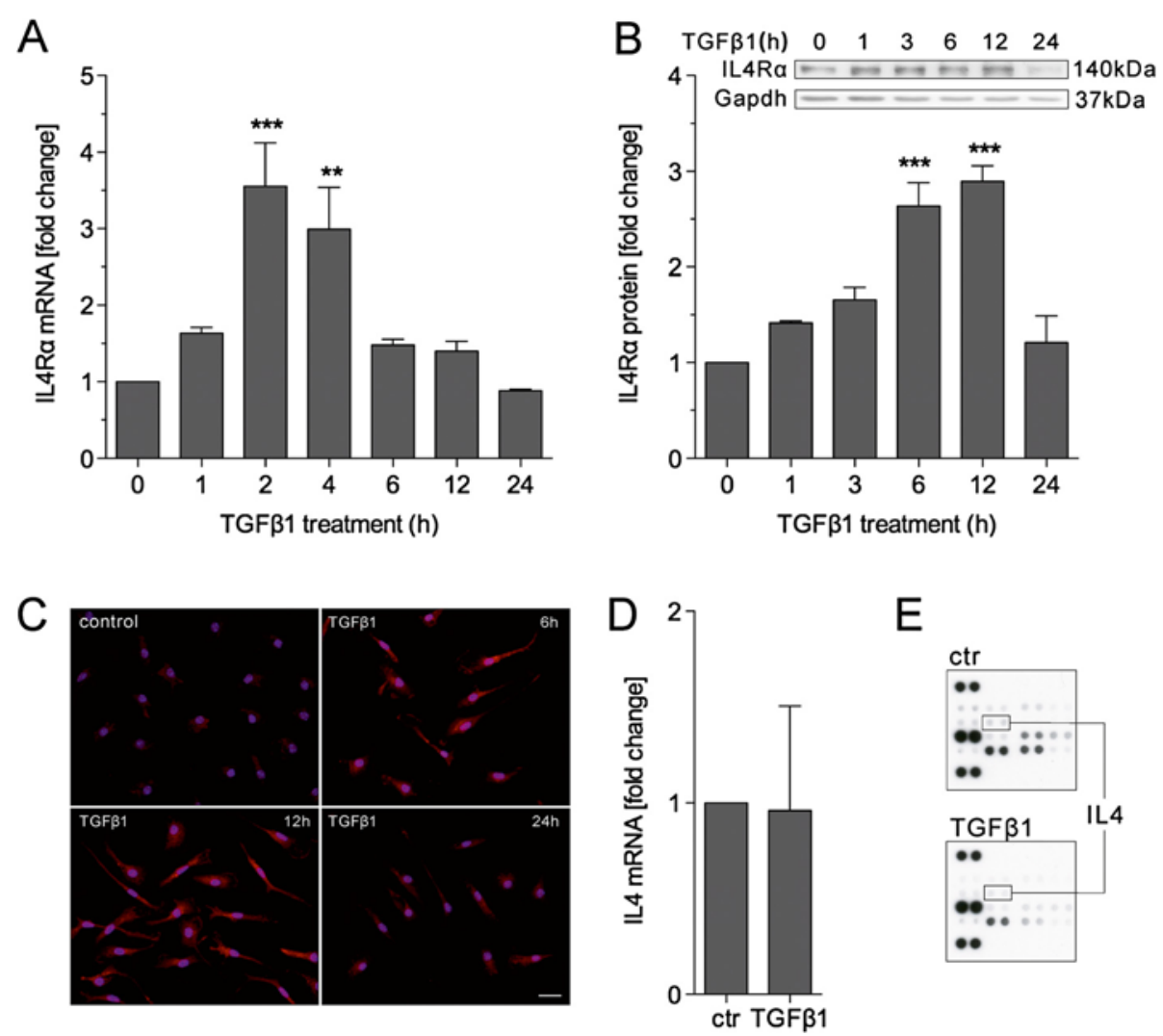

Figure 4 TGF $\beta 1$ up regulates the IL4Ra. Primary microglia were treated with TGF $\beta 1$ ( $1 \mathrm{ng} / \mathrm{ml})$ for different time points and the cells were either harvested for analysing IL4Ra mRNA and protein levels, or fixed with 4\% paraformaldehyde (PFA) for IL4Ra immunostaining. Quantitative RT-PCR showed that treatment with TGF $\beta 1$ increased IL4Ra mRNA levels starting after 1 hour and peaking at around 2 hours. Afterwards mRNA levels decreased again and returned to basal levels at 24 hours (A). Western blotting showed IL4Ra protein expression starting to increase after treatment with TGF $\beta 1$ for 1 hour and peaking at around 6 to 12 hours after treatment (B). After treatment with TGF $\beta 1$ for 6 and 12 hours, IL4Ra immunoreactivity (red) was increased and cell morphology changed towards a ramified phenotype compared to control cells. After 24 hours, the IL4Ra immunoreactivity (red) was decreased but the cells still presented a ramified shape with long processes (C). Scale represents $20 \mu \mathrm{m}$. Treatment of primary microglia with TGF $\beta 1(n=5)$ had no effect on IL4 mRNA levels (D). Analysis of TGF $\beta 1$-mediated changes in microglial cytokine release $(n=2)$ demonstrated no differences in IL4 levels after TGF $\beta 1$ treatment $(\mathbf{E})$. Data $(\mathbf{A}, \mathbf{B}, \mathbf{D})$ are presented as means \pm standard error: ${ }^{* *} P<0.01,{ }^{* * *} P<0.001$ (one-way analysis of variance).

microglia were treated with IL4, TGF $\beta 1$ and IL4/TGF $\beta 1$ in the absence or presence of the MEK1/2 inhibitor PD98059 for 24 hours. Western blotting results from BV2 cells showed that IL4 treatment alone increased Arg1 protein levels, which was partially inhibited in the presence of PD98059. TGF $\beta 1$ and IL4 co-treatment increased IL4-induced Arg1 protein levels and the MEK1/2 inhibitor PD89059 partially blocked the TGF 1 1-mediated increase in Arg1 protein levels (Figure 6A). Using primary microglia we confirmed the results obtained with BV2 cells. Treatment with IL4 significantly increased the protein levels of Arg1. Interestingly, in the presence of PD89059, IL4 failed to increase the protein levels of Arg1. Combination of IL4 and TGF $\beta 1$ dramatically increased the protein levels of Arg1 compared to IL4 treatment alone. However, in the presence of the MEK1/2 inhibitor PD89059, TGF $\beta 1$ - enhanced Arg1 up regulation was significantly impaired and the amount of Arg1 was similar to the levels after treatment with IL4 alone (Figure 6B, C). These data demonstrate that TGF $\beta 1$-activated MAPK signalling is essential for TGF $\beta 1$-mediated enhancement of IL4induced Arg1 expression in microglia.

\section{Discussion}

In this study we demonstrate for the first time that TGF $\beta$ enhances the IL4-induced alternative activation of microglia. Using Arg1 and Ym1 as established markers for alternative activation $[3,11]$ we provide evidence that IL4-mediated up-regulation of Arg1 and Ym1 is significantly enhanced in the presence of TGF $\beta 1$. Further, IL4 treatment resulted in increased expression and secretion of TGF $\beta 2$, whereas TGF $\beta$ treatment of microglia increased the expression of the IL4R $\alpha$. Moreover, 

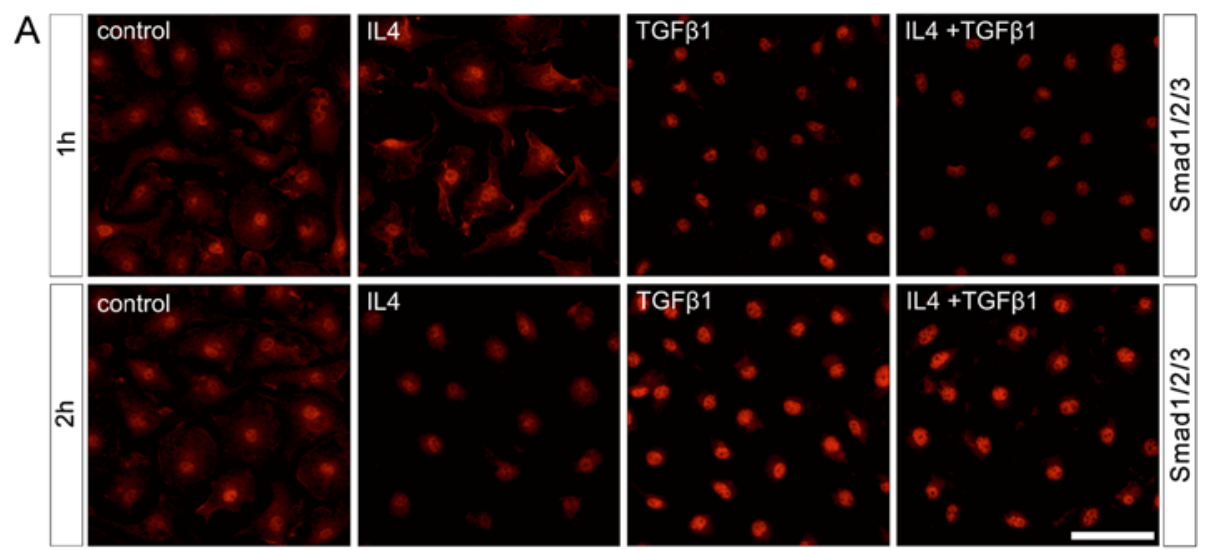

B

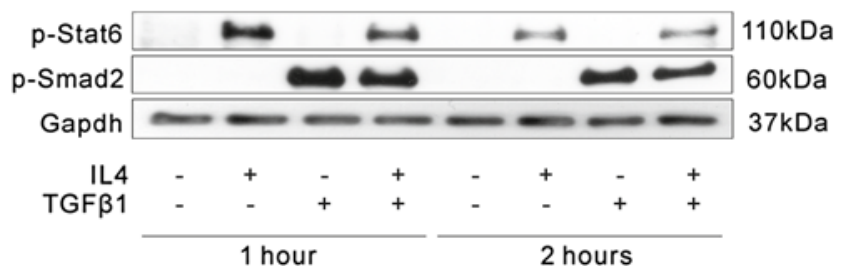

Figure 5 Direct interactions were not observed between the TGF $\beta / S m a d$ signalling pathway and the IL4/Stat6 signalling pathways. Primary microglial cells were treated with either with IL4 $(10 \mathrm{ng} / \mathrm{ml})$, TGF 1 1 $(1 \mathrm{ng} / \mathrm{ml})$ alone or together for 1 and 2 hours. The cells were either fixed with $4 \%$ paraformaldehyde (PFA) for pSmad2/3 immunostaining or harvested for testing pStat 6 and pSmad2 levels. The treatment of TGF $\beta 1$ alone or TGF $\beta 1$ combining IL4-induced pSmad2/3 nuclear translocation both at 1 and 2 hours while IL4 treatment alone was not able to induced pSmad2/3 nuclear translocation (A). Western blotting showed that IL 4 treatment alone exclusively induced Stat6 phosphorylation but not Smad2 phosphorylation after 1 and 2 hours, while TGF $\beta 1$ treatment alone or TGF $\beta 1$ in combination with IL4 only, induced Smad2 phosphorylation but not Stat6 phosphorylation (B).

blocking the TGF- $\beta$ receptor type I resulted in significantly impaired Arg1 and Ym1 up-regulation after IL4 treatment. Finally, we demonstrate that TGF $\beta$-mediated enhancement of Arg1 expression in microglia is dependent on the MAP kinase pathway.

In parallel to transcriptional regulation of microglia markers, the morphological changes are used to discriminate between different activation states in vivo and in vitro. In the resting or inactive state, microglia present a ramified morphology with several processes, while stimulation with classical activation factors such as LPS or IFN $\gamma$ results in retraction of microglial processes and development of an amoeboid phenotype [33,34]. Although changes in morphology also suggest changes in the functional states of microglia, the morphology alone cannot be used to predict a functional outcome. Therefore, we analysed Arg1 and Ym1 as markers for macrophage and microglia alternative activation. Arg1 has been shown to be localised in the cytoplasm of hepatocytes where it is involved in nitrogen elimination by catalysing arginine hydrolysis to urea and ornithine $[11,35]$. Unlike the constitutively expressed Arg1 in the liver, Arg1 in macrophages and microglia is induced by exogenous stimuli including the Th2 cytokines IL4 and IL13 [36,37]. Arg1 inhibits NO production by competing with the inducible nitric oxide synthase (iNOS) for the common substrate L-arginine [38]. On the other hand, the production of ornithine can be used to generate polyamines, glutamate, and proline, the latter being a substrate for the formation of extracellular matrix proteins such as collagen [38-40]. Interestingly, apart from involvement in the regulation of wound healing and fibrosis [41,42], Arg1 can directly support neuron survival [43]. Next to Arg1, Ym1 is another established marker for microglia alternative activation [2,44]. Ym1 is a heparin/heparin sulphate-binding lectin that is transiently expressed during inflammation [44] and although the precise functions of $\mathrm{Ym} 1$ remain elusive, recent reports have suggested an involvement in tissue remodelling and regulation of inflammation $[45,46]$.

TGF $\beta$ has been shown to either up-regulate Arg1 expression or increase the Arg1 enzymatic activity in a cell type-dependent manner. Whereas TGF $\beta$ treatment results in increased expression of Arg1 in fibroblasts and epithelial cells [47-49], TGF $\beta$ strongly increases enzyme activity in macrophages [50,51]. In this study we demonstrate that TGF $\beta 1$ alone is not able to significantly increase expression of Arg1 and Ym1 in microglia. However, in the presence of IL4, TGF $\beta 1$ significantly enhanced IL4-induced Arg1 and Ym1 expression, which indicates the potential role of TGF $\beta$ in CNS tissue repair 


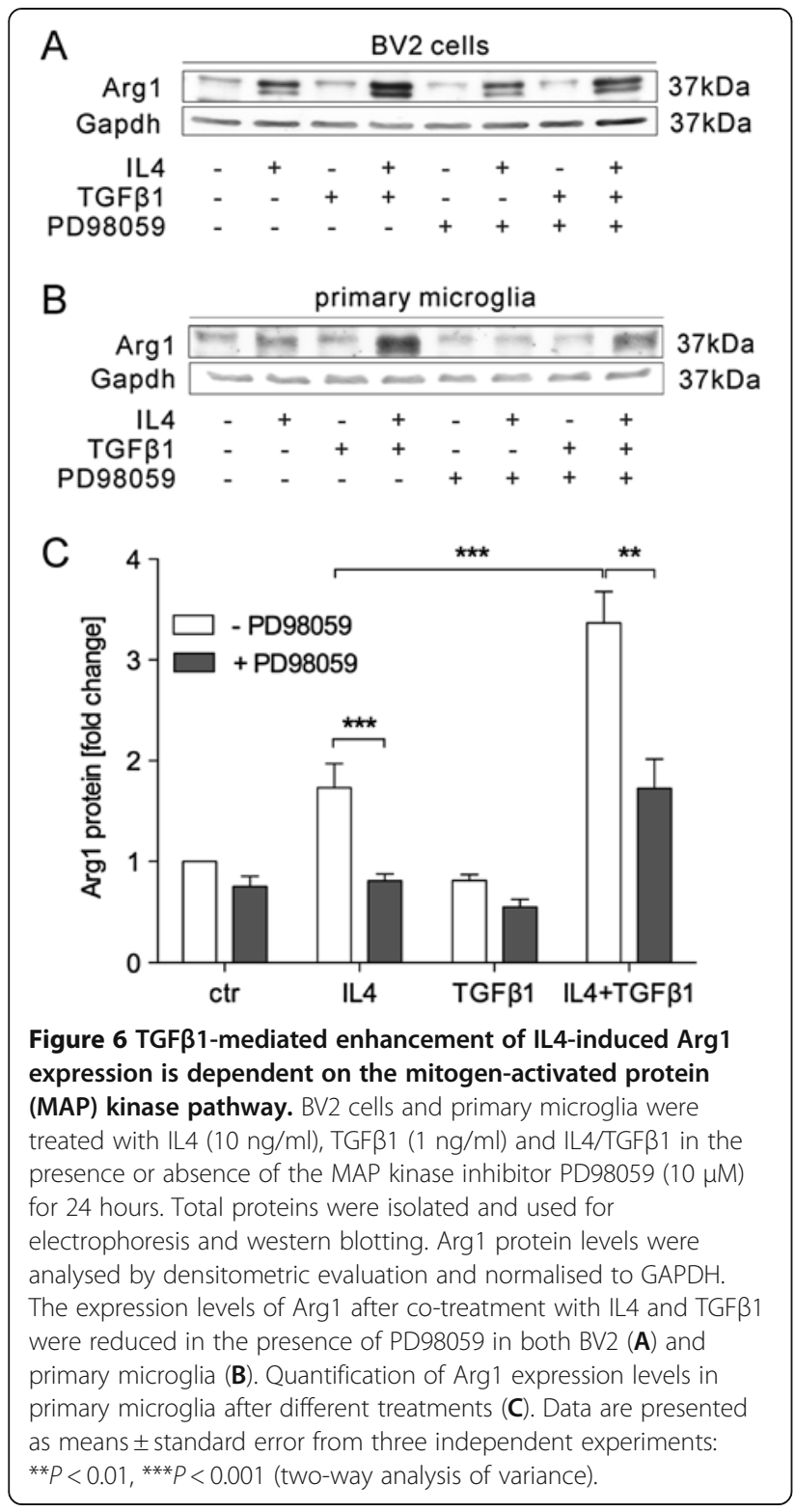

and neurorestoration by modulating alternative activation of microglia.

To understand the mechanisms behind this phenomenon we addressed the question of whether TGF $\beta$ interferes with the IL4 signalling pathway. We demonstrated that TGF $\beta 1$ treatment alone up regulated the common receptor for IL4 and IL13, IL4R $\alpha$, both at mRNA and protein levels in a time-dependent manner. Opposite to the effect of TGF $\beta 1$ on IL4R $\alpha$ expression, IL4 treatment alone reduced IL4R $\alpha$ expression with treatment time (data not shown). Further, we observed that TGF $\beta 1$ was able to enhance the expression of Arg1 induced by IL13 (data not shown) and IL4. These data indicate that the synergistic effect of TGF $\beta 1$ and IL4 on the expression of Arg1 might partially be mediated by enhanced IL4R $\alpha$ expression after TGF $\beta 1$ treatment, thereby increasing the sensitivity of microglia for IL4. IL4 signalling is further propagated by phosphorylation of the transcription factor Stat6 [11,31]. Analysis of Stat6 phosphorylation revealed that TGF $\beta 1$ failed to induce Stat6 phosphorylation. Moreover, IL4 was not able to induce Smad2 phosphorylation in microglia, indicating that the synergistic effect of TGF $\beta 1$ and IL4 on the expression of Arg1 could not be explained by the direct interaction of the TGF $\beta /$ Smad and IL4/Stat6 signalling pathways. Therefore, we further investigated if a TGF $\beta$ induced Smad-independent pathway, the MAPK pathway, is involved in this synergistic effect. By performing a pharmaceutical blockage of the TGF $\beta$-induced MAPK pathway using the MEK1/2 inhibitor PD98059, we could show that the Arg1 protein expression, not only induced by TGF $\beta 1$ and IL 4 co-treatment but also induced by IL 4 treatment alone, were significantly inhibited in the presence of PD98059. These data clearly demonstrate that TGF $\beta$ signalling is involved in IL4-induced microglia alternative activation and an essential role of TGF $\beta$ mediated MAPK pathway in the enhancement of IL-4 induced microglia alternative activation by TGF $\beta$ signalling.

We observed that IL4 treatment of microglia lead to up regulation of TGF $\beta 2$, whereas the mRNA levels of TGF $\beta 1$ and TGF $\beta 3$ were not changed after IL4 treatment. TGF $\beta 2$ levels were significantly increased in the supernatants of IL4-treated microglia. Although most of the secreted TGF $\beta 2$ was in a latent and inactive form, a small proportion of bioactive TGF $\beta 2$ seems to be sufficient to support IL4-induced up regulation of Arg1 and Ym1. However, microglia express several factors and enzymes that are capable of activating latent TGF $\beta$ s, such as integrins, plasminogen, MMP2 and thrombospondin1 (unpublished data). Moreover, microglia also express extracellular matrix components in vitro that might bind TGF $\beta$. This amount of bound, and probably activated, TGF $\beta$ will escape all analyses of the microglial supernatant, but is likely to activate TGF $\beta$ signalling in these cells.

It is widely accepted that TGF $\beta$ is involved in the down regulation of microglia classical activation. TGF $\beta 1$ reduces reactive oxygen species (ROS) induced by LPS and suppresses the IFN $\gamma$-induced expression of MHC II and the production of cytokines, IL1, IL6, and TNFalpha production in activated microglia [52,53]. TGF $\beta$ also prevents IL1 $\beta$-induced microglial activation [54]. Although the anti-inflammatory role of TGF $\beta$ has been widely accepted, it is still quite ambiguous whether this effect is beneficial or detrimental in terms of different CNS diseases. Whereas TGF $\beta 1$ has protective and beneficial functions in cerebral ischaemia [55], it promotes 


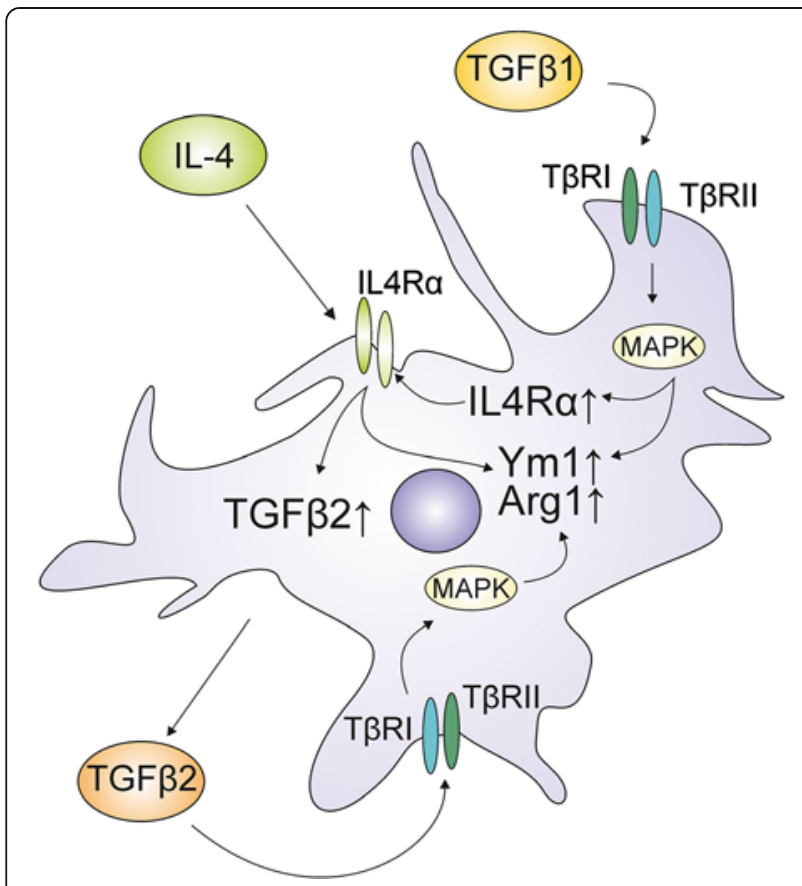

Figure 7 Proposed model for the role of TGF $\beta$ in IL4-induced alternative microglia activation. $\| L 4$ induces expression of the alternative activation markers Ym1 and Arg1 via the IL4Ra-Stat6 pathway. TGF $\beta$ binds to its receptors TGF $\beta$ type I and type II, which form a heteromeric complex and initiate Smad-dependent and Smad-independent pathways. Exogenous TGF $\beta 1$ enhances IL4induced $\mathrm{Ym} 1$ and Arg1 expression either by a direct effect on Ym1/ Arg1 promoter activity or indirectly by up regulating the IL $4 R a$ through activation of the MAP kinase (Smad-independent) pathway. Furthermore, IL4 treatment alone increased endogenous TGF $\beta 2$ expression and secretion. Autocrine TGF $\beta 2$ in turn might be able to enhance IL4-induced Arg1 expression by using similar signalling mechanisms to exogenous TGF $\beta 1$.

the deposition of amyloid-beta plaques in models of Alzheimer's disease [56]. Interestingly, Town and colleagues have demonstrated that blocking of TGF $\beta /$ Smad signalling almost completely abrogated the plaque formation in transgenic mice overexpressing mutant human amyloid precursor protein [57]. These results underline the importance of a tight temporal and spatial regulation of innate immune responses and further demonstrate the necessity to enhance our knowledge of the pathological conditions under which TGF $\beta$-mediated regulation of inflammation is beneficial or detrimental.

Whereas TGF $\beta$ induces acquired deactivation, the acquired deactivation macrophages also produce TGF $\beta$ in an autocrine manner $[3,24,25]$. Next to down regulating the classical activation of microglia, here we show, for the first time, that the TGF $\beta$ also enhances IL4induced microglia alternative activation in vitro, which broadens the knowledge of interactions among different microglia activation states. Similar functions have been shown for another immunoregulatory cytokine, IL10. For example, IL10 is able to impair IFN $\gamma$-induced macrophage classical activation [58], increase arginase activities [59], and further enhance IL4-induced Arg1 expression, probably by increasing IL4R $\alpha$ expression [60]. Findings of this work and previous studies suggest an interaction and dynamic change between different microglia activation states. TGF $\beta$ might serve as a gatekeeper to inhibit classical activation and promote alternative activation of microglia. The data presented throughout this study confirm the role of TGF $\beta$ as an anti-inflammatory molecule and broaden its functions as an enhancer of microglia alternative activation, thereby regulating microgliamediated neuroregeneration and neurorestoration in inflammatory CNS diseases.

\section{Conclusions}

Here we show, for the first time, that TGF $\beta 1$ synergises IL4 in the induction of microglia alternative activation. We demonstrate that IL4 treatment increased the expression and secretion of TGF $\beta 2$ in primary microglia and that IL4-induced up regulation of Arg1 and $\mathrm{Ym} 1$ is dependent on active TGF $\beta$ signalling. Finally, we provide evidence that MAPK signalling is involved in TGF $\beta$-mediated enhancement of IL4induced microglia alternative activation. Figure 7 shows a proposed model for the role of TGF $\beta$ in microglia alternative activation. Our findings provide novel insights into the molecular mechanisms of IL4-induced microglia alternative activation, and further enhance our knowledge of TGF $\beta$-mediated modulation of microglial functions.

\section{Abbreviation}

AD: Alzheimer's disease; Arg1: Arginase1; Ym1: Chitinase 3-like 3; CNS: Central nervous system; DAPI: 41,6-diamidino-2-phenylindole; DMEM: Dubecco's modified Eagle medium; ELISA: Enzyme-linked immunosorbent assay; FBS: Fetal bovine serum; FCS: Fetal calf serum; GAPDH: Glyceraldehyde-3phosphate dehydrogenase; LPS: Lipopolysaccharide; M1: Classical activation of microglia; M2: Alternative activation of microglia; MAPK: Mitogen-activated protein kinase; MCM: Microglial conditioned medium; MLEC: Mink lung epithelial cell; MMP: Matrix metalloproteinase; M-PER: Mammalian protein extraction reagent; MS: Multiple sclerosis; NO: Nitric oxide; P/S: Penicillin/ streptomycin; PAl: Plasminogen activator inhibitor; PBS: Phosphate-buffered saline; PD: Parkinson's disease; PFA: Paraformaldehyde; PVDF: Polyvinylidene difluoride; ROS: Reactive oxygen/nitrogen species; TNFa: Tumour necrosis factor-alpha.

\section{Competing interests}

The authors declare that they have no competing interests.

\section{Authors' contributions}

XZ conceived of the study idea. XZ carried out all the experiments. BS participated in the experiments. XZ, BS and KK were involved in conception and design of the study as well as in the manuscript preparation. All authors have read and approved the final manuscript.

\section{Acknowledgments}

This study was supported by grants from the Deutsche Forschungsgemeinschaft (KK, Kr1477/10-3). The authors thank Susanna Glaser for excellent assistance. The article processing charge was funded by the 
German Research Foundation (DFG) and the Albert Ludwigs University Freiburg in the funding programme Open Access Publishing.

\section{Author details}

${ }^{1}$ Institute for Anatomy and Cell Biology, Department of Molecular Embryology, Albert-Ludwigs-University Freiburg, Albertstraße 17, Freiburg 79104, Germany. ${ }^{2}$ Faculty of Biology, Albert-Ludwigs-University Freiburg, Hauptstraße 1, 79104 Freiburg, Germany. ${ }^{3}$ Freiburg Institute for Advanced Studies (FRIAS), Albert-Ludwigs-University Freiburg, Albertstraße 19, Freiburg 79104, Germany.

Received: 23 February 2012 Accepted: 17 August 2012

Published: 4 September 2012

\section{References}

1. Vaughan DW, Peters A: Neuroglial cells in the cerebral cortex of rats from young adulthood to old age: an electron microscope study. J Neurocytol 1974, 3:405-429.

2. Colton CA, Mott RT, Sharpe $H, X u$ Q, Van Nostrand WE, Vitek MP: Expression profiles for macrophage alternative activation genes in $A D$ and in mouse models of AD. J Neuroinflammation 2006, 3:27.

3. Colton CA, Wilcock DM: Assessing activation states in microglia. CNS Neurol Disord Drug Targets 2010, 9:174-191.

4. Shimizu E, Kawahara K, Kajizono M, Sawada M, Nakayama H: IL-4-induced selective clearance of oligomeric beta-amyloid peptide(1-42) by rat primary type 2 microglia. J Immunol 2008, 181:6503-6513.

5. Ponomarev ED, MaresZ K, Tan Y, Dittel BN: CNS-derived interleukin-4 is essential for the regulation of autoimmune inflammation and induces a state of alternative activation in microglial cells. J Neurosci 2007, 27:10714-10721

6. Ponomarev ED, Veremeyko T, Barteneva N, Krichevsky AM, Weiner HL: MicroRNA-124 promotes microglia quiescence and suppresses EAE by deactivating macrophages via the C/EBP-alpha-PU.1 pathway. Nat Med 2011, 17:64-70.

7. Rojo Al, Innamorato NG, Martin-Moreno AM, De Ceballos ML, Yamamoto $M$, Cuadrado A: Nrf2 regulates microglial dynamics and neuroinflammation in experimental Parkinson's disease. Glia 2010, 58:588-598.

8. Smith PF: Inflammation in Parkinson's disease: an update. Curr Opin Investig Drugs 2008, 9:478-484.

9. Rubartelli A, Lotze MT: Inside, outside, upside down: damage-associated molecular-pattern molecules (DAMPs) and redox. Trends Immunol 2007, 28:429-436.

10. Mosser DM: The many faces of macrophage activation. J Leukoc Biol 2003, 73:209-212.

11. Gordon S: Alternative activation of macrophages. Nat Rev Immunol 2003, 3:23-35.

12. Gao HM, Hong JS: Why neurodegenerative diseases are progressive: uncontrolled inflammation drives disease progression. Trends Immunol 2008, 29:357-365.

13. Giulian D: Ameboid microglia as effectors of inflammation in the central nervous system. J Neurosci Res 1987, 18:155-171. 132-153.

14. Block ML, Zecca L, Hong JS: Microglia-mediated neurotoxicity: uncovering the molecular mechanisms. Nat Rev Neurosci 2007, 8:57-69.

15. Town T, Nikolic $V$, Tan J: The microglial "activation" continuum: from innate to adaptive responses. J Neuroinflammation 2005, 2:24.

16. Town T: Alternative Abeta immunotherapy approaches for Alzheimer's disease. CNS Neurol Disord Drug Targets 2009, 8:114-127.

17. Gordon S, Taylor PR: Monocyte and macrophage heterogeneity. Nat Rev Immunol 2005, 5:953-964.

18. Martinez FO, Helming L, Gordon S: Alternative activation of macrophages: an immunologic functional perspective. Annu Rev Immunol 2009, 27:451-483.

19. Bogdan C, Vodovotz Y, Nathan C: Macrophage deactivation by interleukin 10. J Exp Med 1991, 174:1549-1555.

20. Williams $L$, Jarai $G$, Smith $A$, Finan $P:$ IL-10 expression profiling in human monocytes. J Leukoc Biol 2002, 72:800-809.

21. Li MO, Wan YY, Sanjabi S, Robertson AK, Flavell RA: Transforming growth factor-beta regulation of immune responses. Annu Rev Immunol 2006, 24:99-146.
22. Gregory CD, Devitt A: The macrophage and the apoptotic cell: an innate immune interaction viewed simplistically? Immunology 2004, 113:1-14.

23. Griffiths MR, Gasque P, Neal JW: The multiple roles of the innate immune system in the regulation of apoptosis and inflammation in the brain. J Neuropathol Exp Neurol 2009, 68:217-226.

24. Mosser DM, Edwards JP: Exploring the full spectrum of macrophage activation. Nat Rev Immunol 2008, 8:958-969.

25. Fadok VA, Bratton DL, Konowal A, Freed PW, Westcott JY, Henson PM: Macrophages that have ingested apoptotic cells in vitro inhibit proinflammatory cytokine production through autocrine/paracrine mechanisms involving TGF-beta, PGE2, and PAF. J Clin Invest 1998, 101:890-898.

26. Blobe GC, Schiemann WP, Lodish HF: Role of transforming growth factor beta in human disease. N Engl J Med 2000, 342:1350-1358.

27. Feng $X H$, Derynck R: Specificity and versatility in tgf-beta signaling through Smads. Annu Rev Cell Dev Biol 2005, 21:659-693.

28. Massague J, Gomis RR: The logic of TGFbeta signaling. FEBS Lett 2006 580:2811-2820

29. Engel ME, McDonnell MA, Law BK, Moses HL: Interdependent SMAD and JNK signaling in transforming growth factor-beta-mediated transcription. J Biol Chem 1999, 274:37413-37420.

30. Abe M, Harpel JG, Metz CN, Nunes I, Loskutoff DJ, Rifkin DB: An assay for transforming growth factor-beta using cells transfected with a plasminogen activator inhibitor-1 promoter-luciferase construct. Anal Biochem 1994, 216:276-284.

31. Oh CK, Geba GP, Molfino N: Investigational therapeutics targeting the IL-4/IL-13/STAT-6 pathway for the treatment of asthma. Eur Respir Rev 2010, 19:46-54.

32. Le $Y$, Iribarren $P$, Gong W, Cui $Y$, Zhang X, Wang JM: TGF-beta1 disrupts endotoxin signaling in microglial cells through Smad3 and MAPK pathways. J Immunol 2004, 173:962-968.

33. Loane DJ, Stoica BA, Pajoohesh-Ganji A, Byrnes KR, Faden Al: Activation of metabotropic glutamate receptor 5 modulates microglial reactivity and neurotoxicity by inhibiting NADPH oxidase. J Biol Chem 2009, 284: 15629-15639.

34. Kitamura Y, Takahashi H, Matsuoka Y, Tooyama I, Kimura H, Nomura Y, Taniguchi T: In vivo induction of inducible nitric oxide synthase by microinjection with interferon-gamma and lipopolysaccharide in rat hippocampus. Glia 1996, 18:233-243.

35. Wynn TA: Fibrotic disease and the $\mathrm{T}(\mathrm{H}) 1 / \mathrm{T}(\mathrm{H}) 2$ paradigm. Nat ReV Immunol 2004, 4:583-594.

36. Munder M, Eichmann K, Modolell M: Alternative metabolic states in murine macrophages reflected by the nitric oxide synthase/arginase balance: competitive regulation by CD4+ T cells correlates with Th1/Th2 phenotype. J Immunol 1998, 160:5347-5354.

37. Pauleau AL, Rutschman R, Lang R, Pernis A, Watowich SS, Murray PJ: Enhancer-mediated control of macrophage-specific arginase I expression. J Immunol 2004, 172:7565-7573.

38. Morris SM Jr: Enzymes of arginine metabolism. J Nutr 2004, 134:2743S-2747S. discussion 2765S-2767S.

39. Gotoh T, Sonoki T, Nagasaki A, Terada K, Takiguchi M, Mori M: Molecular cloning of cDNA for nonhepatic mitochondrial arginase (arginase II) and comparison of its induction with nitric oxide synthase in a murine macrophage-like cell line. FEBS Lett 1996, 395:119-122.

40. Kepka-Lenhart D, Ash DE, Morris SM: Determination of mammalian arginase activity. Methods Enzymol 2008, 440:221-230.

41. Loke P, Gallagher I, Nair MG, Zang X, Brombacher F, Mohrs M, Allison JP, Allen JE: Alternative activation is an innate response to injury that requires CD4+ T cells to be sustained during chronic infection. J Immunol 2007, 179:3926-3936.

42. Hesse M, Modolell M, La Flamme AC, Schito M, Fuentes JM, Cheever AW, Pearce EJ, Wynn TA: Differential regulation of nitric oxide synthase-2 and arginase- 1 by type 1/type 2 cytokines in vivo: granulomatous pathology is shaped by the pattern of L-arginine metabolism. J Immunol 2001, 167:6533-6544.

43. Ma TC, Campana A, Lange PS, Lee HH, Banerjee K, Bryson JB, Mahishi L, Alam S, Giger RJ, Barnes S, Morris SM Jr, Willis DE, Twiss JL, Filbin MT, Ratan RR: A large-scale chemical screen for regulators of the arginase 1 promoter identifies the soy isoflavone daidzeinas a clinically approved small molecule that can promote neuronal protection or 
regeneration via a CAMP-independent pathway. J Neurosci 2010, 30:739-748.

44. Chang NC, Hung SI, Hwa KY, Kato I, Chen JE, Liu CH, Chang AC: A macrophage protein, $\mathrm{Ym} 1$, transiently expressed during inflammation is a novel mammalian lectin. J Biol Chem 2001, 276:17497-17506

45. Giannetti N, Moyse E, Ducray A, Bondier JR, Jourdan F, Propper A, Kastner A: Accumulation of $Y \mathrm{~m} 1 / 2$ protein in the mouse olfactory epithelium during regeneration and aging. Neuroscience 2004, 123:907-917.

46. Nio J, Fujimoto W, Konno A, Kon Y, Owhashi M, Iwanaga T: Cellular expression of murine $\mathrm{Ym} 1$ and $\mathrm{Ym} 2$, chitinase family proteins, as revealed by in situ hybridization and immunohistochemistry. Histochem Cell Biol 2004, 121:473-482.

47. Kitowska K, Zakrzewicz D, Konigshoff M, Chrobak I, Grimminger F, Seeger W, Bulau P, Eickelberg O: Functional role and species-specific contribution of arginases in pulmonary fibrosis. Am J Physiol Lung Cell Mol Physiol 2008 294:L34-L45.

48. Witte MB, Barbul A, Schick MA, Vogt N, Becker HD: Upregulation of arginase expression in wound-derived fibroblasts. J Surg Res 2002, 105:35-42.

49. Jiang J, George SC: TGF-\{beta\}2 reduces nitric oxide synthase mRNA through a ROCK-dependent pathway in airway epithelial cells. Am J Physiol Lung Cell Mol Physiol 2011, 301:L361-7.

50. Boutard V, Havouis R, Fouqueray B, Philippe C, Moulinoux JP, Baud L: Transforming growth factor-beta stimulates arginase activity in macrophages. Implications for the regulation of macrophage cytotoxicity. J Immunol 1995, 155:2077-2084.

51. Shearer JD, Richards JR, Mills CD, Caldwell MD: Differential regulation of macrophage arginine metabolism: a proposed role in wound healing. Am J Physiol 1997, 272:E181-190.

52. Suzumura A, Sawada M, Yamamoto H, Marunouchi T: Transforming growth factor-beta suppresses activation and proliferation of microglia in vitro. J Immunol 1993, 151:2150-2158.

53. Herrera-Molina R, von Bernhardi R: Transforming growth factor-beta 1 produced by hippocampal cells modulates microglial reactivity in culture. Neurobiol Dis 2005, 19:229-236.

54. Basu A, Krady JK, Enterline JR, Levison SW: Transforming growth factor beta1 prevents IL-1beta-induced microglial activation, whereas TNFalpha- and IL-6-stimulated activation are not antagonized. Glia 2002, 40:109-120.

55. Dhandapani KM, Brann DW: Transforming growth factor-beta: a neuroprotective factor in cerebral ischemia. Cell Biochem Biophys 2003, 39:13-22.

56. Wyss-Coray T, Masliah E, Mallory M, McConlogue L, Johnson-Wood K, Lin C, Mucke L: Amyloidogenic role of cytokine TGF-beta1 in transgenic mice and in Alzheimer's disease. Nature 1997, 389:603-606.

57. Town T, Laouar Y, Pittenger C, Mori T, Szekely CA, Tan J, Duman RS, Flavell RA: Blocking TGF-beta-Smad2/3 innate immune signaling mitigates Alzheimer-like pathology. Nat Med 2008, 14:681-687.

58. Colton CA: Heterogeneity of microglial activation in the innate immune response in the brain. J Neuroimmune Pharmacol 2009, 4:399-418.

59. Lumeng $C N$, Bodzin $J$, Saltiel AR: Obesity induces a phenotypic switch in adipose tissue macrophage polarization. J Clin Invest 2007, 117:175-184.

60. Lang R, Patel D, Morris JJ, Rutschman RL, Murray PJ: Shaping gene expression in activated and resting primary macrophages by IL-10. $\mathrm{J}$ Immunol 2002, 169:2253-2263.

\section{Submit your next manuscript to BioMed Central and take full advantage of:}

- Convenient online submission

- Thorough peer review

- No space constraints or color figure charges

- Immediate publication on acceptance

- Inclusion in PubMed, CAS, Scopus and Google Scholar

- Research which is freely available for redistribution

Submit your manuscript at www.biomedcentral.com/submit
C Biomed Central 